\title{
Research Paper \\ The Effect of Group Cognitive Rehabilitation Therapy on the Problem Solving Skills of Students with Attention Deficit Hyperactivity Disorder
}

Tina Mohammadi" ${ }^{*}$, Gholam Ali Afrouz ${ }^{2}$

1. Ph.D. Student of Psychology and Education of Exceptional Children, Faculty of Psychology and Educational Sciences, Allameh Tabataba'i University, Tehran, Iran

2. Professor, Department of Psychology of Exceptional Children, Faculty of Psychology and Educational Sciences, University of Tehran, Iran

Citation: Mohammadi T, Afrouz GA. The effect of group cognitive rehabilitation therapy on the problem solving skills of students with attention deficit hyperactivity disorder. Quarterly Journal of Child Mental Health. 2020; 7(2): 144-155

http://dx.doi.org/10.29252/jcmh.7.2.13

\section{A R T I C L E I N F O}

\section{Keywords:}

Group cognitive rehabilitation therapy, problem-solving, attention deficit hyperactivity disorder (ADHD)

Received: 26 May 2019

Accepted: 4 Mar 2020

Available: 21 Sep 2020

\section{A B S T R A C T}

Background and Purpose: Research has shown that children with Attention Deficit Hyperactivity Disorder (ADHD) lack problem-solving skills to face with problems in different situations. Different techniques have been used to treat and rehabilitate these children. This study aimed to investigate the effect of group cognitive rehabilitation therapy on problem-solving skills of students with ADHD.

Method: This research was a quasi-experimental study with pretest-posttest control group design. The study population included all the students with ADHD who were studying in District 12 of Tehran during the first semester of academic year 2017-2018. A sample of 30 students was selected by convenience sampling based on inclusion and exclusion criteria and then randomly assigned to either the experimental or control group (15 per group). The experimental group underwent ten 30 45-min sessions of group cognitive rehabilitation therapy, while the control group received no intervention. Child Symptom Inventory (Sprafkin \& Gadow, 1994) and London Tower Test (Shalis, 1984) were used to collect the data. Data were analyzed by ANCOVA.

Results: Findings showed that group cognitive rehabilitation therapy had a significant effect on improving the problem-solving skills of students with ADHD ( $\mathrm{p}<0.01)$.

Conclusion: Based on the results of this study which indicated the effect of group cognitive rehabilitation therapy on problem-solving skills of students with ADHD, it can be concluded that via reinforcing the brain areas related to attention and concentration, this therapeutic method can improve the academic and behavioral performance of these children.

\footnotetext{
* Corresponding author: Tina Mohammadi, Ph.D. Student of Psychology and Education of Exceptional Children, Faculty of Psychology and Educational Sciences, Allameh Tabataba'i University, Tehran, Iran.

E-mail addresses: Tinaa_mohammadi@yahoo.com
} 


\title{
تأثير توانبخشى شناختى كروهى بر توانايى حل مسئله در دانش آموزان با اختلال نارسايى توجه/ فزون كنشى
}

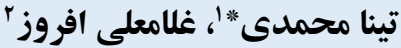 \\ ا. دانشجوى دكتراى روانشناسى و آموزش كود كان استثنايى، دانشكده روانشناسى و علوم تربيتى، دانشكاه علامه طباطبائى، تهران، ايران انئان

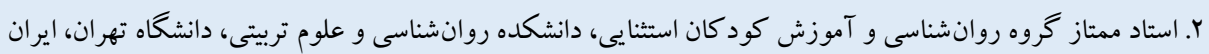

\begin{tabular}{|c|c|}
\hline جكيده & 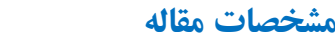 \\
\hline زمينه و هدف: يُزوهشها نشان دادند كه يكى از مشكلات اصلى كودكان مبتلا به اختلال نارسايى توجه/ فزونكنشى، مشكلات آنها در & كليدوازهها: \\
\hline مهارت هاى حل مسئله در موقعيت هاى مختلف است. شيوههاى مختلفى براى درمان و توانبخشى اين كود كان به كار رفته است، اما اين مطالعه & 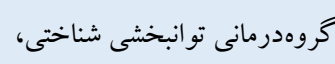 \\
\hline با هدف بررسى تأثير توانبخشى شناختى گروهى بر توانايى حل مسئله دانش آموزان با اختلال نارسايى توجه/فزون كنشى انجام شد. & حل مسئله، \\
\hline 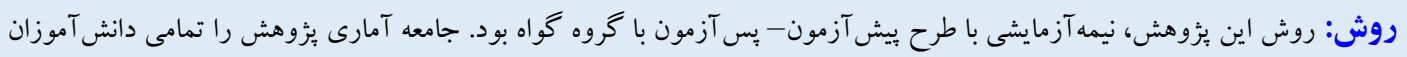 & 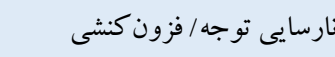 \\
\hline 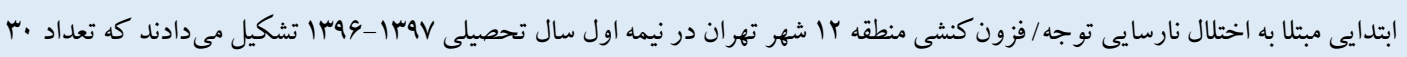 & \\
\hline نفر از آنها به روش نمونه گيرى در دسترس بر حسب شرايط ورود و خروج از نمونه، و در دو گروه آزمايش (ها نفر) و گواه (هانفر) & \\
\hline 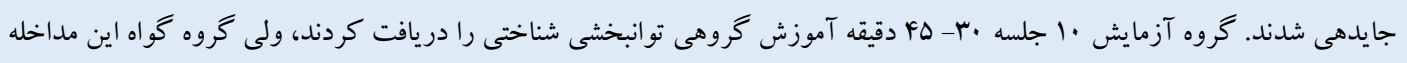 & \\
\hline را دريافت نكرده است. به منظور گردآورى اطلاعات از ير سشنامه علائم مرضى كودكان (اسييرافكين و كادو، 199f) و آزمون برج لندن & \\
\hline (شاليس، 19AY) استفاده شد. تجزيه و تحليل دادها با آزمون تحليل كوواريانس تك متغيره انجام شد. & \\
\hline يافتهها: نتايج تحليل دادهها نشان داد توانبخشى شناختى مبتنى گروهى، تأثير معنادارى بر بهبود تو انايى حل مسئله در دانش آموزان با اختلال & \\
\hline 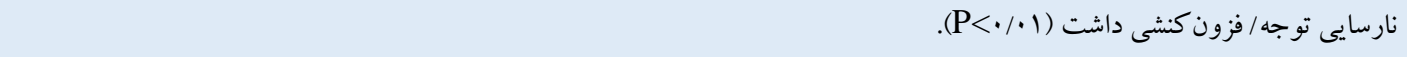 & \\
\hline نتيجه كيرى: با توجه به نتايج اين مطالعه مبنى بر تأثير توانبخشى شناختى مبتنى بر آموزش گروهى بر مهارت هاى حل مسئله در دانش آموزان & 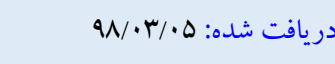 \\
\hline با نارسايى توجه/ فزون كنشى مىتوان نتيجه گيرى كرد كه اين شيوه درمانى با تقويت مناطق مغزى مربوط به توجه و تمر كز باعث بهبود & 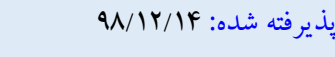 \\
\hline عملكرد اين كود كان در حيطهاى مختلف تحصيلى و رفتارى مىشود. & 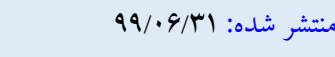 \\
\hline
\end{tabular}

* نويسنده مسئول: تينا محمدى، دانشجوى دكتراى روانشناسى و آموزش كود كان استنايى، دانشكده روانشناسى و علوم تربيتى، دانشكاه علامه طباطبائى، تهران، ايران.

Tinaa_mohammadi@yahoo.com رايانها

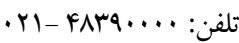


كود كان با اختلال نارسايى توجه/ فزون كنشى براى تعامل بايد بتو انند

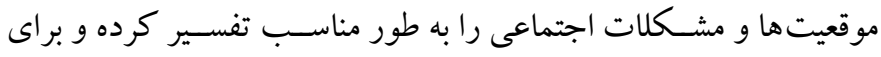

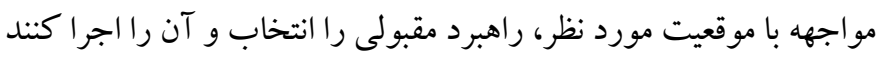
و در واقع از توانيى حل مسئله بهرهمند باشد. نقايص مربوط به حل مسئله

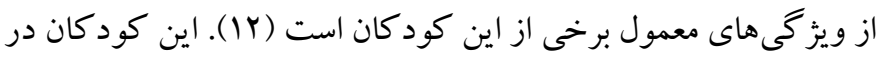

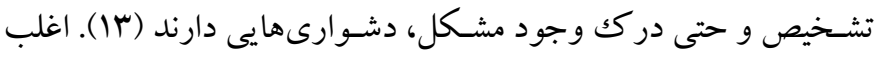

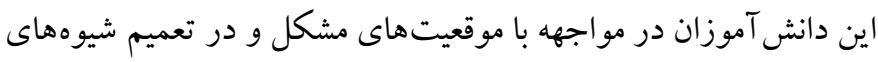

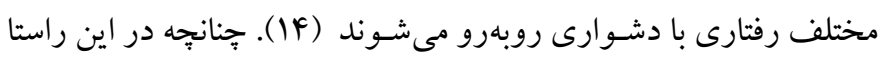

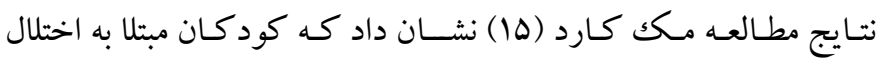

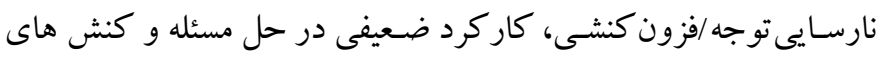

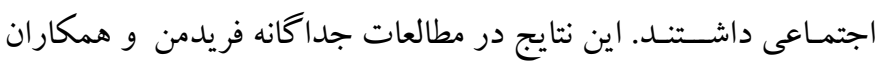

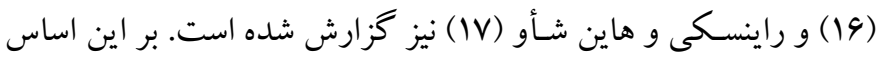

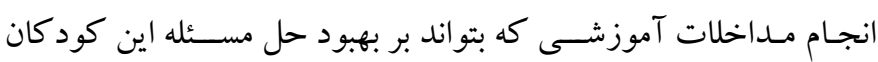

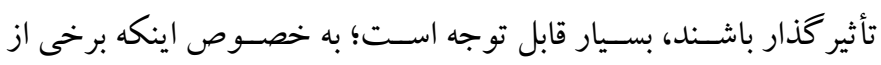

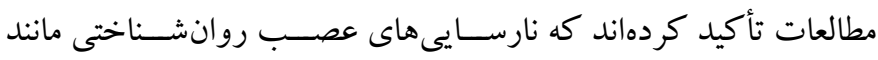
نارسايى در كنشهاى اجر ايى در كود كان دوره ابتدايى مى تواند در سنين

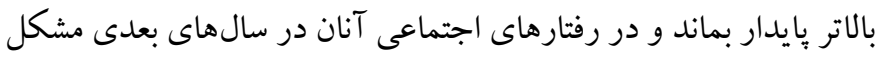
جدى ايجاد كند (1) - (1).

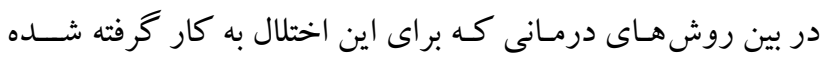

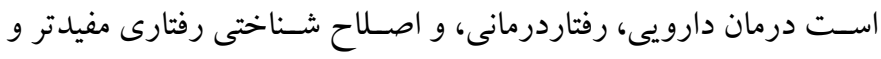

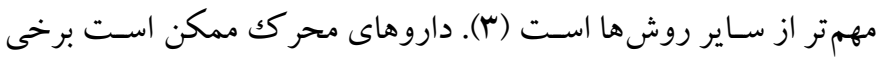

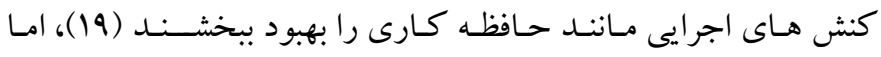

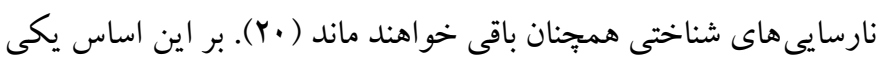

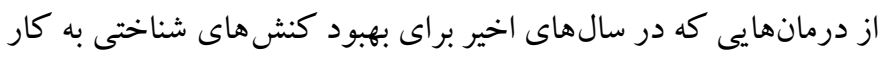

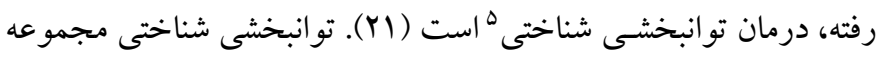

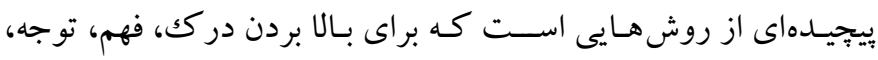

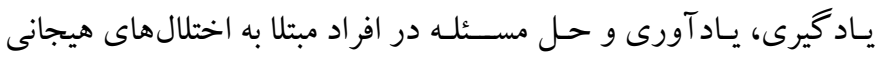
رفتارى طر احى شده است (YY). تو انبخشى شناختى نوعى تجربه ياد ئيرى

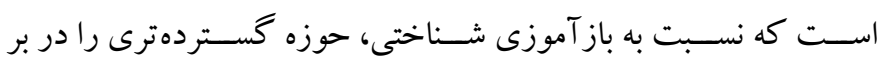

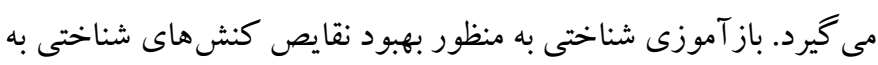

مقلمهه

يكى از رايجترين اختلالهاى عصبى روانيز شكى در دوران كودكى كه

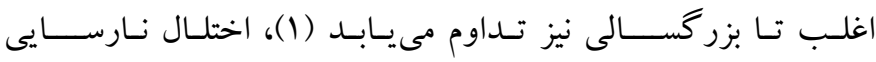
توجه /فزون كنشـى ' اسـت كه با علائم نارسـايى توجه، فزون كنشسى، و و

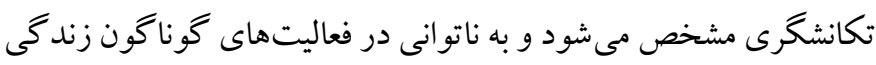

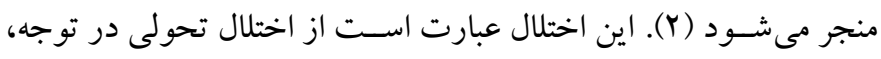

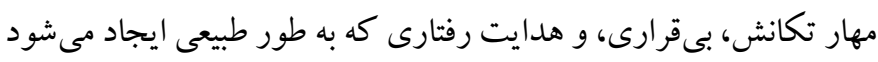

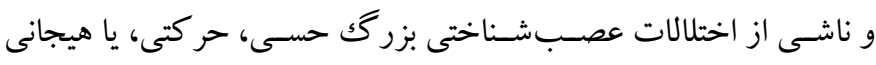

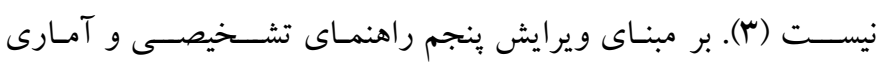

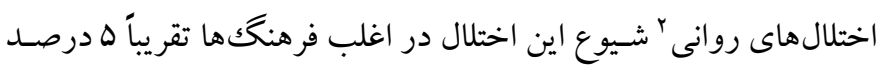

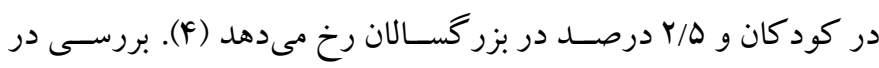

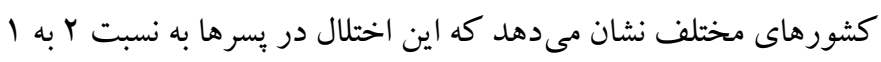

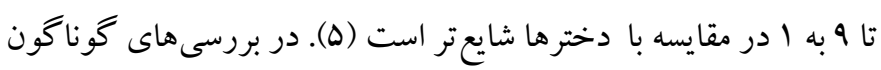

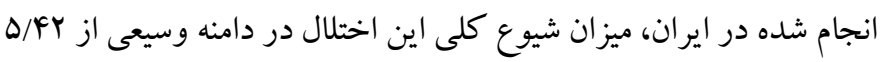

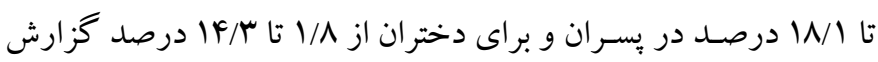
شده است (4، لو و ).

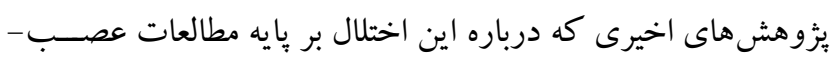

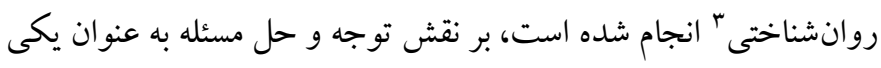

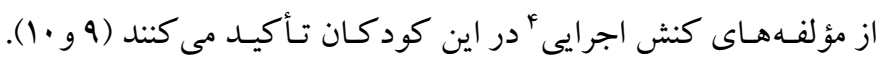

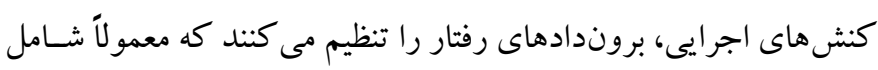
بـازدارى و مهار محر ككهـا، حافظه كارى، انعطاف يذيرى، حلى مل مســئله،

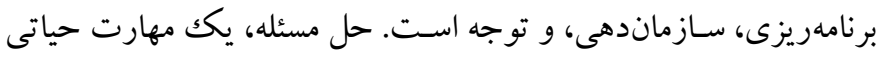
براى زندگى در عصر حاضر است. در اغلب جوامع، همه بر اين عقيدهاند

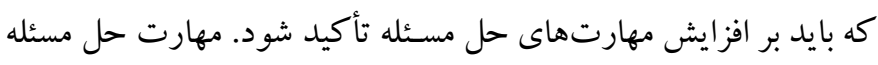
مستلزم راهبردهاى ويزه و هدفمندى است كه فرد به وسيله آن مشكلات بهات

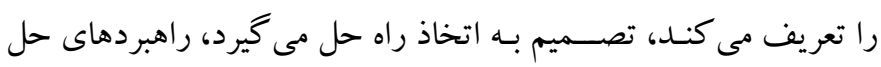

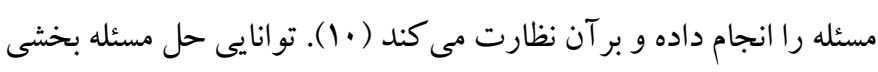

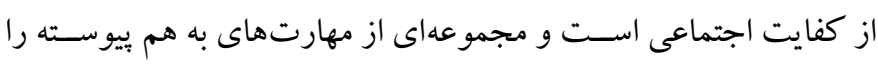
جهت استفاده در حل تضادهاى ميانفردى ارائه مى كند كه مستلزم اقدام به عمل و همجنين واكنش دهى به پاسخ ديخر ان است (11).

1. Attention deficit / hyperactivity disorder

2. Diagnostic of ststidtical manual of mental disorder (5 Th Ed- DsmV) 
با توجه به مشـكلات مربوط به كنش هاى اجرايى در دانش آموزان با

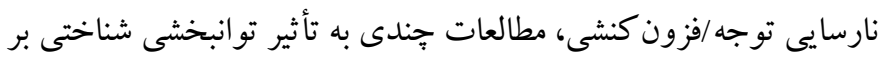

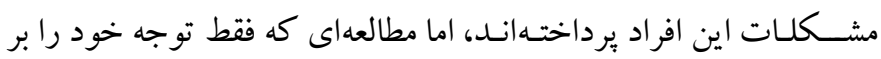
روى توانيى حل مسـئله اين دانش آموزان معطوف كند، و همجِنين نحوه

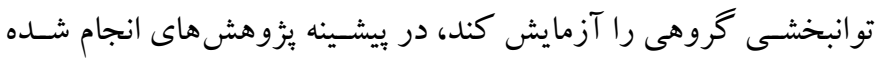
ييدا نشد. در نتيجه با توجه به خلاء ئزوهشى موجود در اين مورد و اهميت تو انيى حل مســئله و نقش آن در جنبه هاى رفتارى اين كود كان، مطالعه

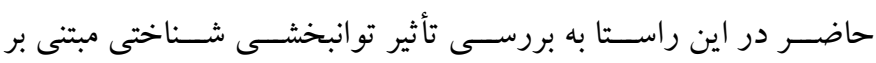

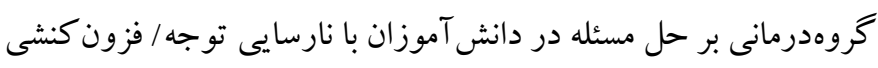

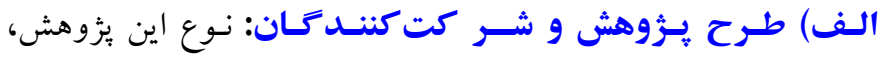

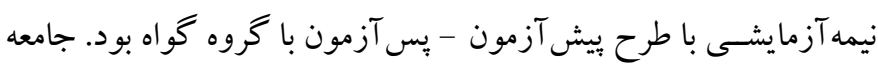

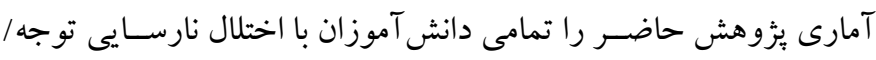

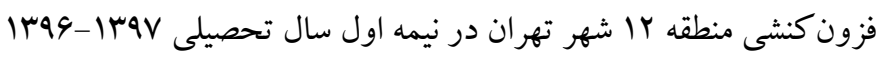

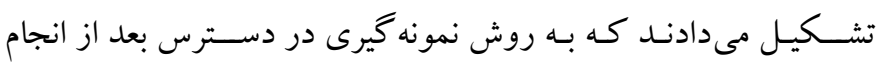

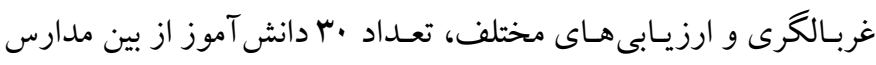

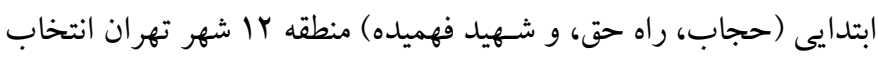

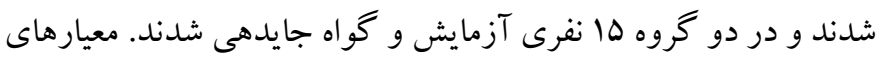

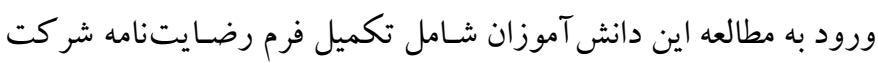

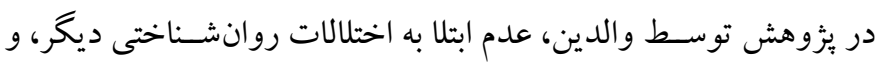

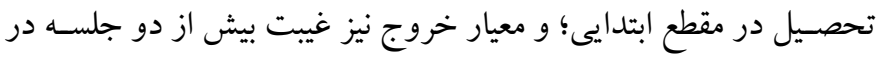

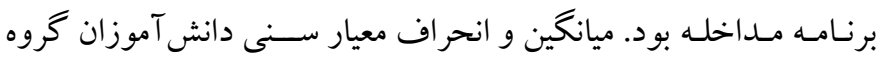

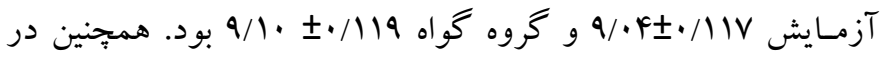

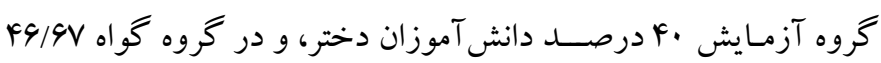

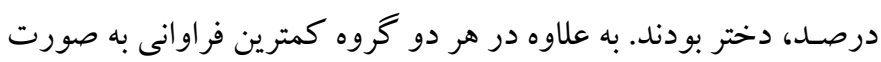

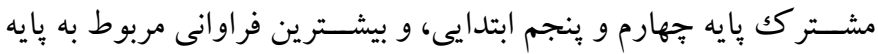

$$
\text { يكم ابتدايى بودند. }
$$

كار برده مىشود، اما در توانبخشى شناختى، انطباق كانشى در فعاليتهاى

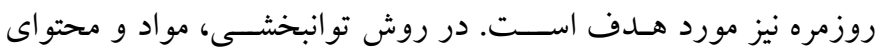

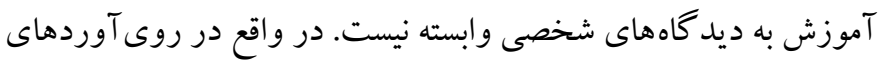

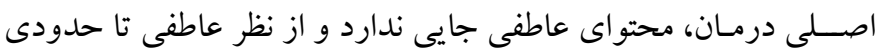

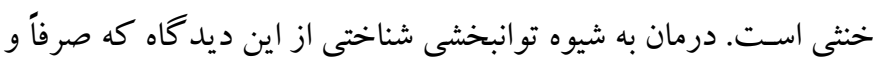

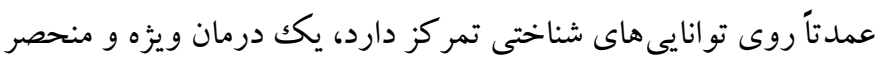

به فرد است (سY).

شـواهد قابل توجهى براى حمايت از روش تو انبخشى شناختى بر ایى

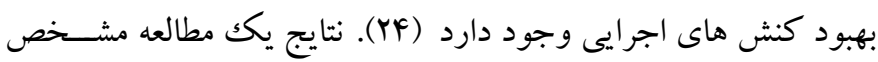

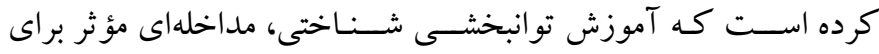

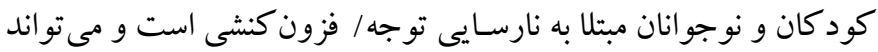

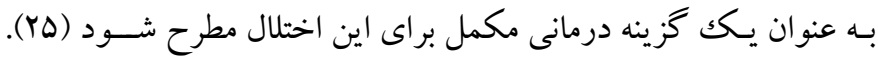

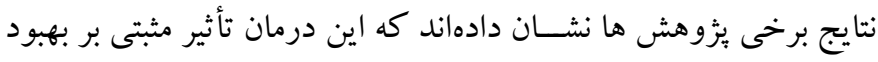
اختلال نارسـايى توجه/فزون كنشى دارد (Y) و TY (YV). به علاوه نتايج مطالعه

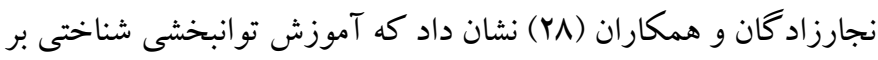

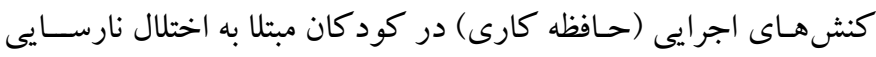
توجه / فزون كنشى تأثير معنادارى دارد. همجينين نريمانى و همكاران (Y9) (Y)

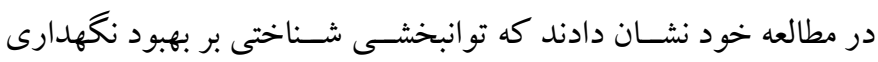
توجه دانش آموزان داراى اختلال نارسـايى توجه/ فزون كنش، مؤثر است.

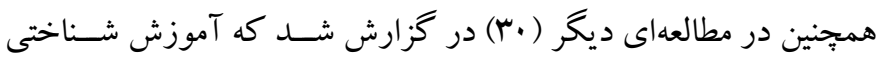

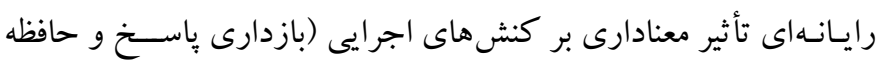

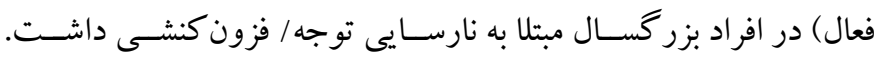

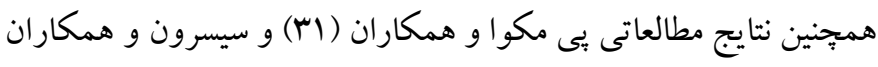

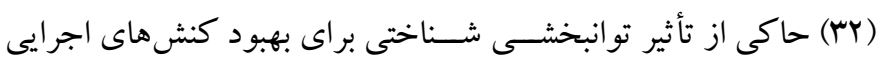

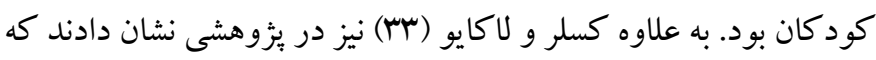

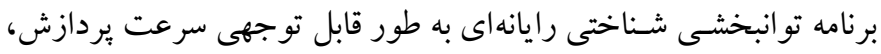

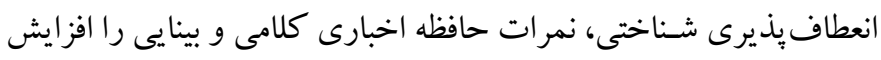

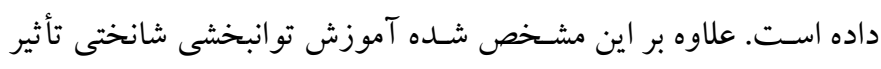

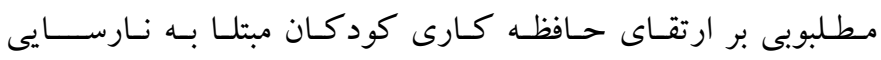

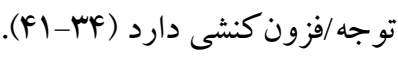




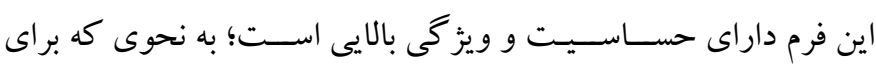

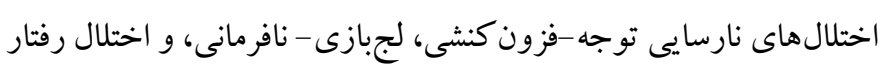

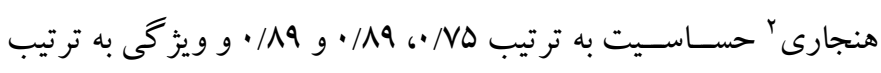

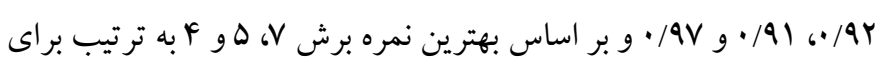

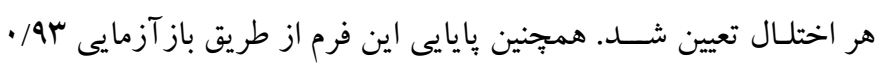

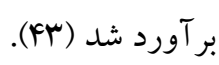

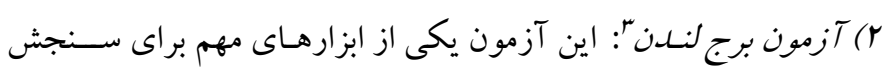

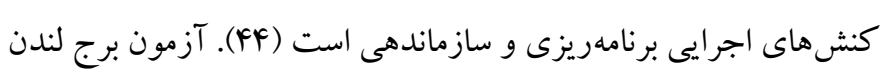

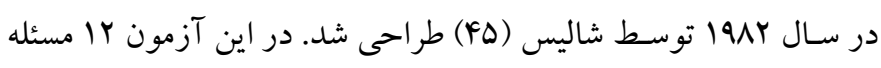

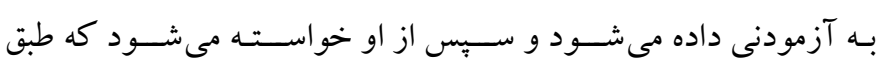

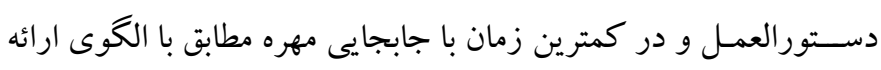

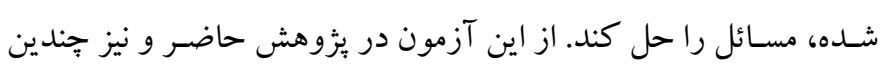

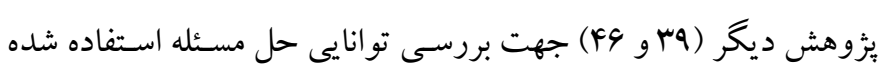

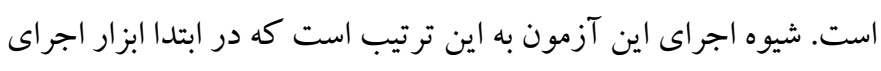

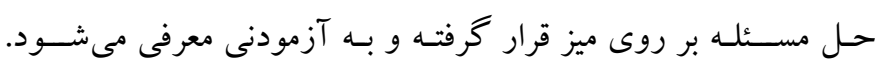

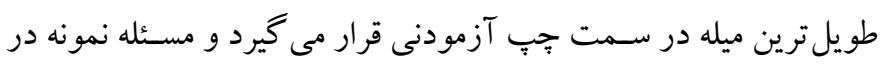

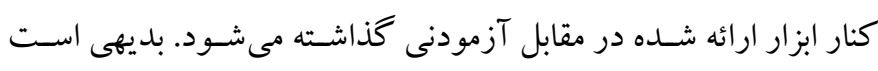

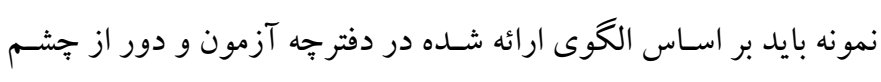
آزمودنى مرتب شود. براى اين كار از يكك صفحه مقو ايى به عنو ان مانع

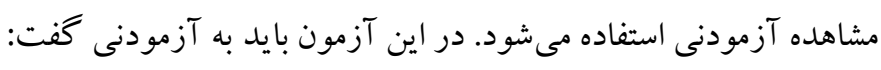

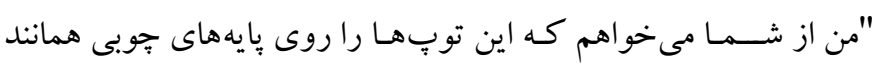

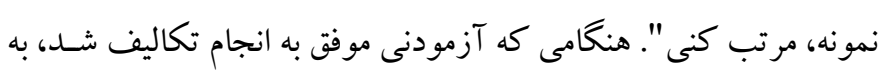

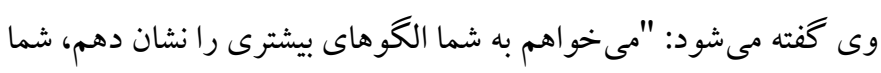

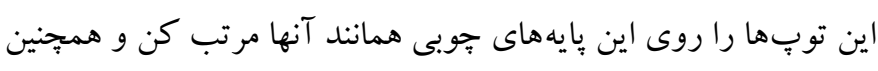

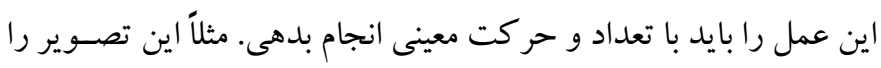

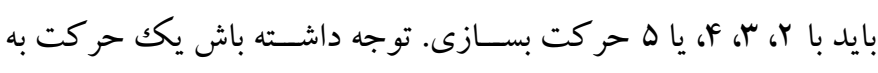

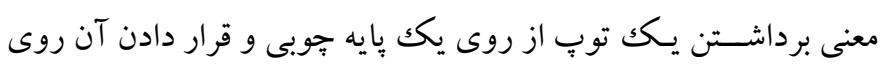

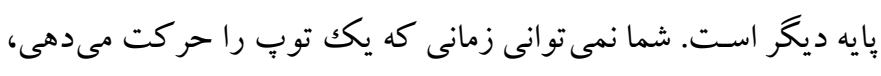

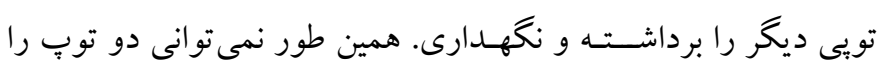

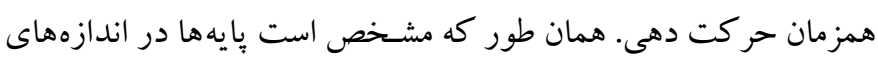

ب) ابزار:

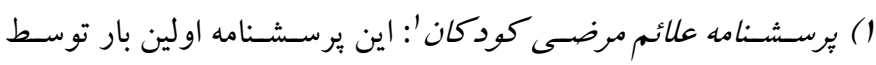

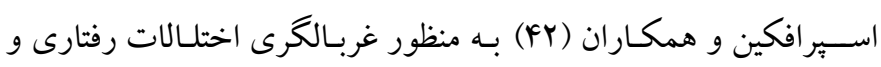

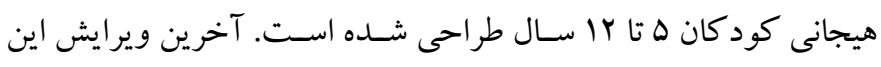

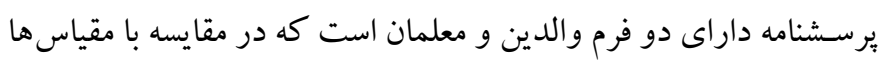

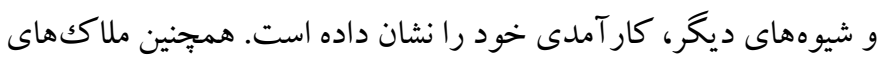

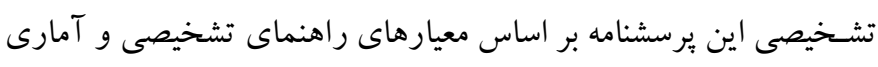

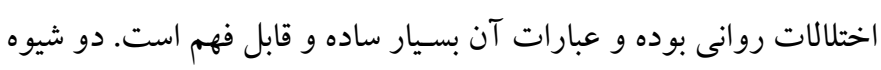

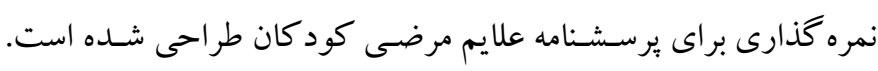

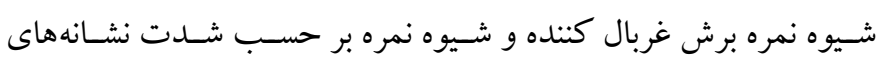

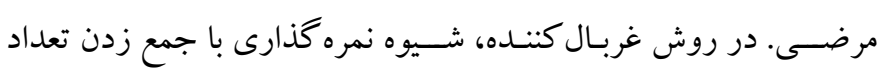

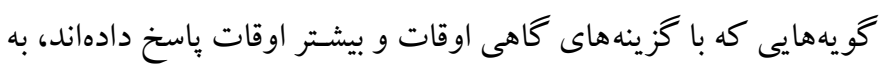

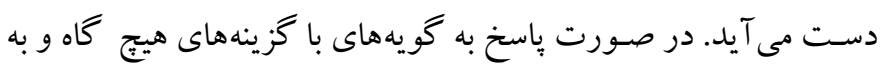

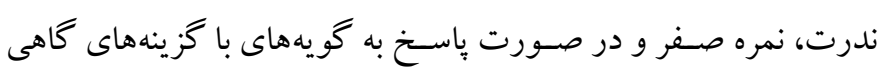

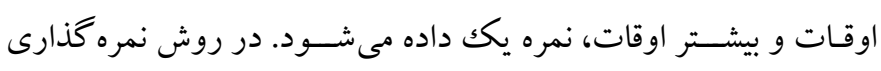

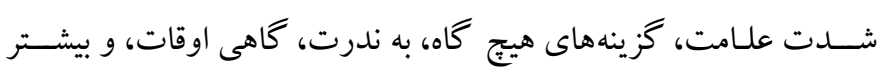

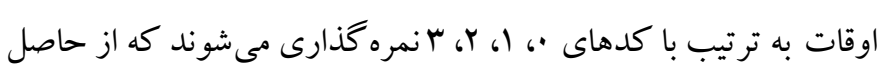

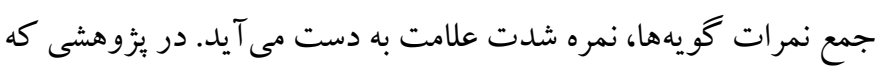

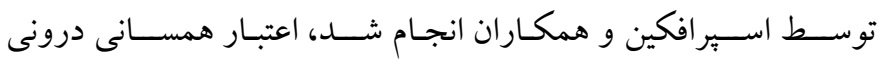

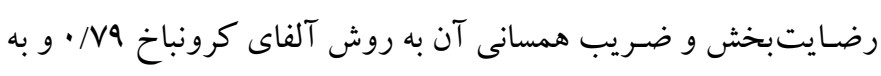

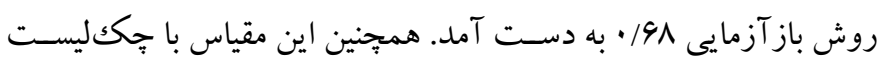

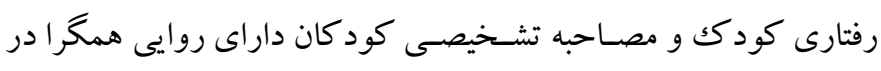

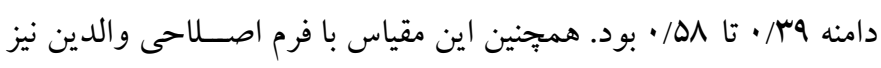

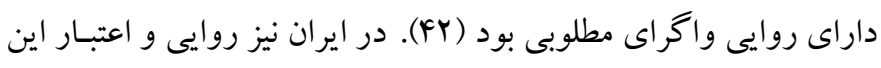

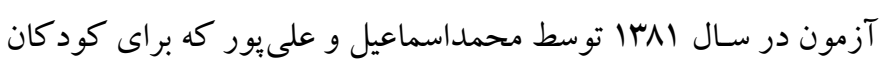

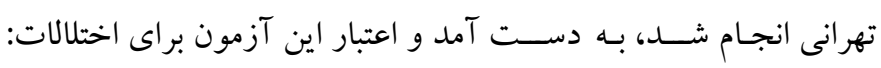

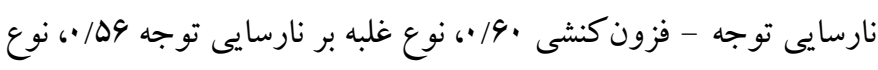

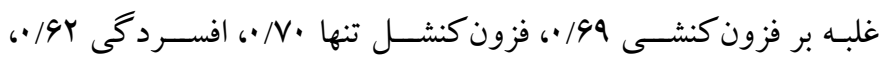

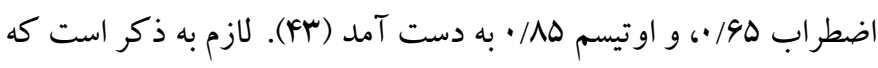

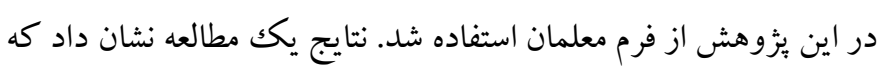

1. Child symptom inventory- 4 (CSI-4)

2. Conduct disorder 
زمان اجرا بالاتر باشـــ، نشـــاندهنده كندى فرد در بردازش اســت و در

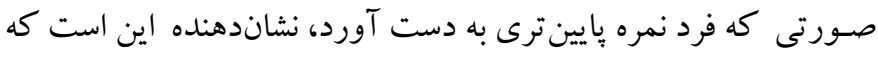

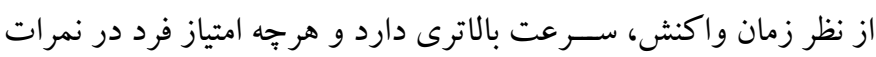
حل مسئله بيشتر باشد، نشاندهنده اين است كه توانسته مسائل بيشترى را حل كند (FA). اعتبار اين آزمون بر اساس ضريب آلفاى كرونباخ برابر باليا

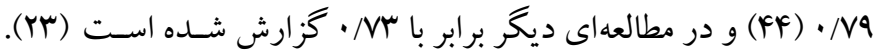
همجِنين در ايران نيز اين مقياس در يُزوهشى ترجمه و مورد استفاده قرار

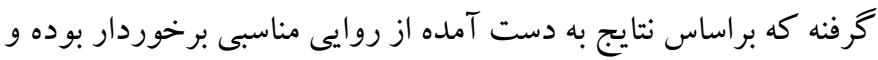

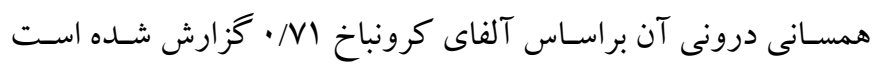

ج) برنـامه مداخلهاى: در اين مطـالعه، بســته درمانى براســاس بســـه

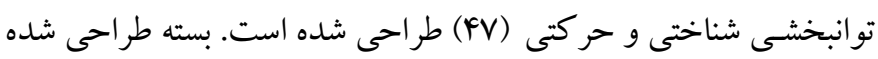
شـامل تمرينات توانبخشى شناختى است كه براى انواع اختلالات استفاده مىشود. اين برنامه شامل · ل جلسه است كه هر جلسه به صورت انفر ادى

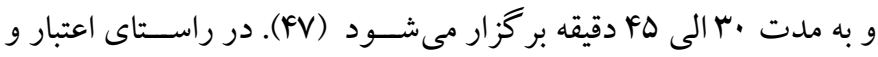

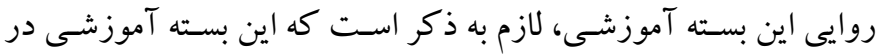

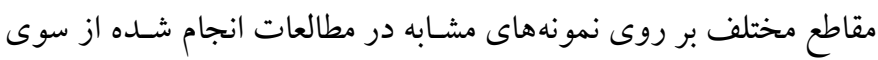

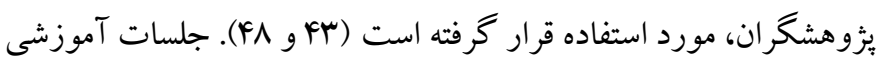
اين بسته به صورت فشرده هفتهاى Y بار (به منظور تراكم بيشتر تمرينات) تشكيل مى شود كه در ادامه خلاصه اين جلسات ارائه شده است:
مختلفى اســت. روى اين يكى هيج يـا يـك توب، اين يكى حداكثر دو

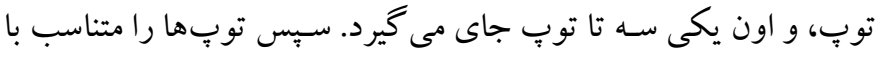

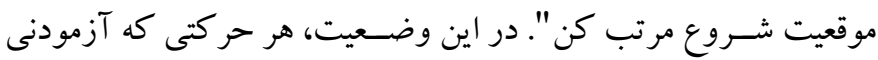

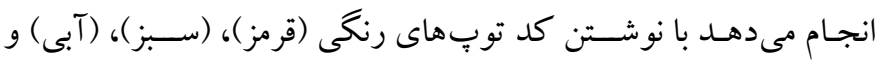

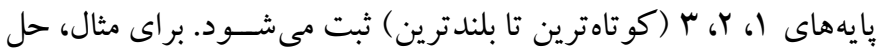

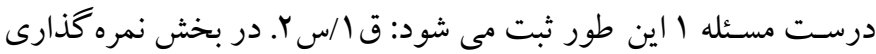

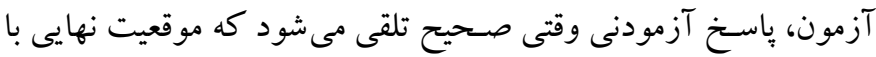
حداقل حر كت (مطابق دستور)، حاصـل شـده باشد. براى حل هر مسئله،

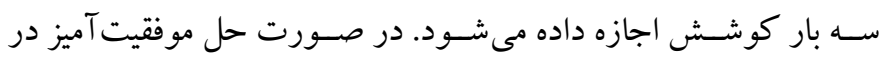
كوشـش نخست بامتياز، در دومين كوشش r امتياز، و در كوشش سوم

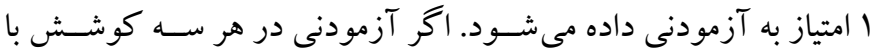

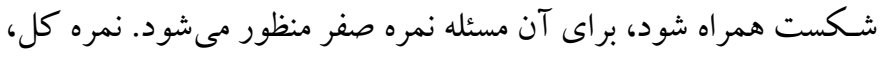

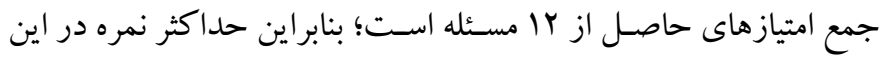

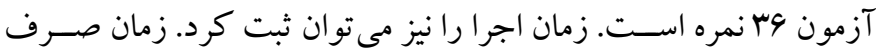

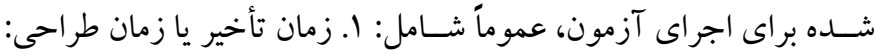

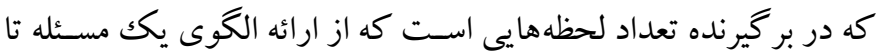

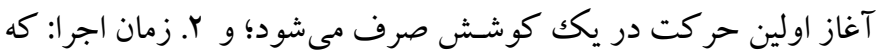
كل لحظـات، از آغـاز اولين حر كات در يكك كوشـش تهـ تا كامل كردن حر كتها در همان كوشش را شامل مى شود. همانطور كه مطرح شد از نمره حاصـل از rا مسـئله ارائه شـــه به فرد براى مقايسـه حل مسـئله در

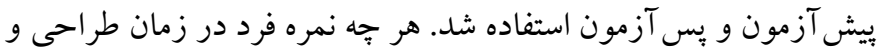

جدول ا: خلاصه جلسات مداخله توانبخشى شناختى

\begin{tabular}{|c|c|c|}
\hline محتوا & 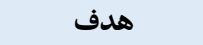 & جلسه \\
\hline معارفه، آشنايى با كود كك و برقرارى ارتباط، اجراى يِيش آزمون (توانايى حل مسئله) & ييش آزمون و معارفه & 1 \\
\hline 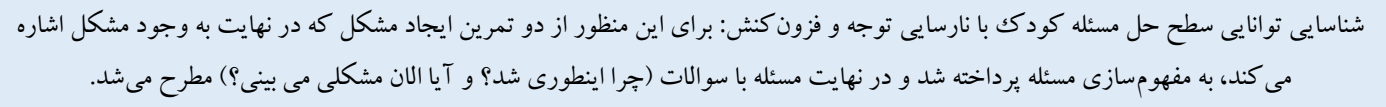 & 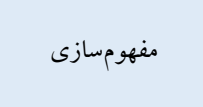 & r \\
\hline در اين جلسه ميزان انعطافيذ يرى ذهنى كودكى با نارسايى توجه/ فزون كنش بررسى مى شد. براى اين منظور از داستانهاى ساده براى جالش كشيدن & انعطاف يذيرى ذهنى إنى & r \\
\hline در اين مر حله مسئلهاى (داستان) به صورت شفاهى در حد سطح انعطاف يذيرى ذهنى كو دك، طراحى شد. همجنين بازى شناختى كارت استفاده شد. & آغاز گرى مسئله & f \\
\hline 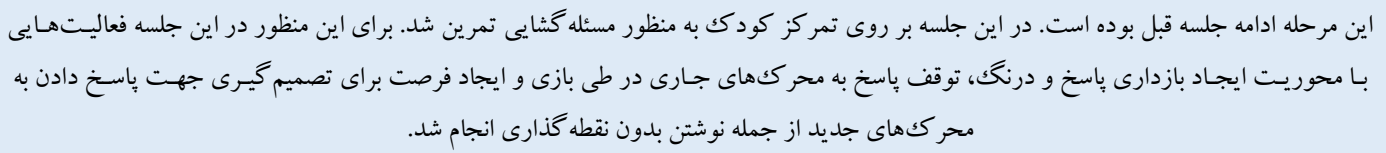 & مسئل كشايى & $\Delta$ \\
\hline 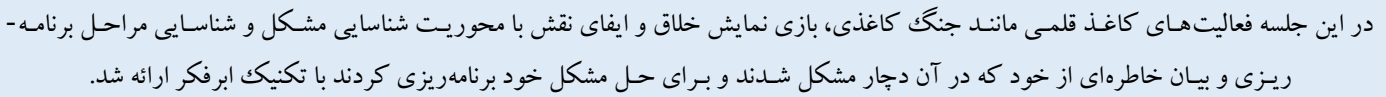 & ادامه مسئله گشايى & 9 \\
\hline
\end{tabular}


در اين جلسه نيز فعاليتهايى بـا محور تقويـت حافظه كارى جهت به خاطر سـيردن بهتر اطلاعـات و كـار كردن روى آنها مانند بازى ينهان كردن و

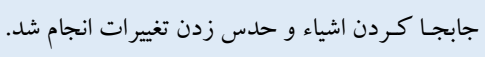

افزايش تمركز

$\checkmark$

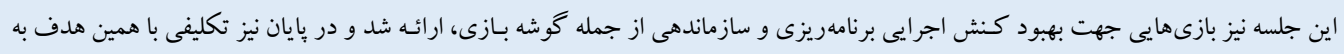
كود كان ارائه شد.

در اين جلسه سعى بر اين شد تا از طريق فعاليتهـاى بازى محور، اشكالات برجسته كود كان رفع شود و به كود كـان نحوه برخو رد صحيح با مشكلات و و

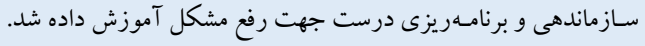

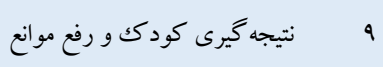

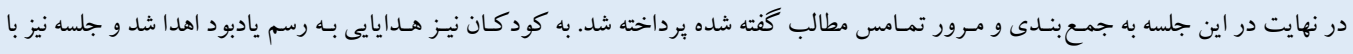

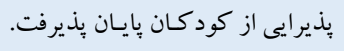

$\quad$ خاتمه جلسات

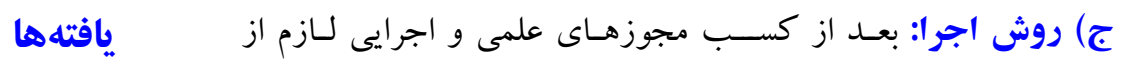

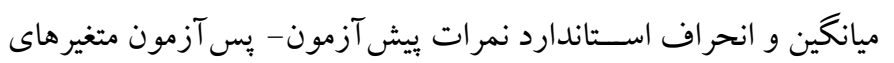

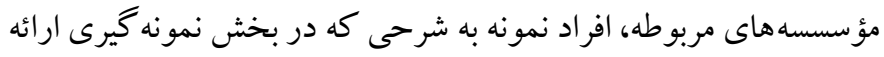

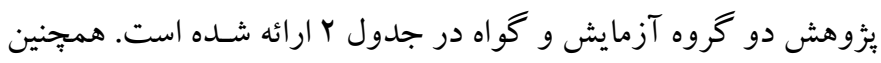

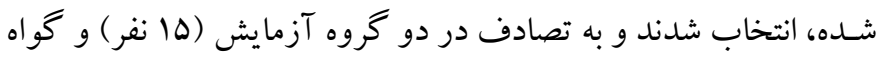

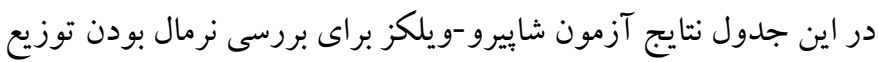

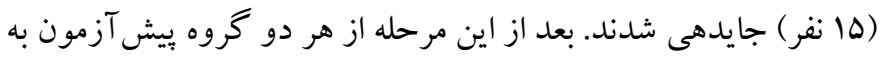

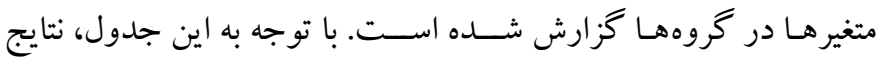

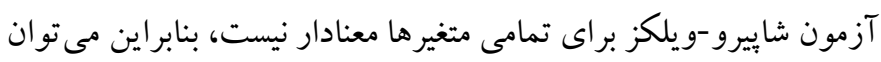
نتيجه گرفت كه توزيع اين متغيرها نرمال است.

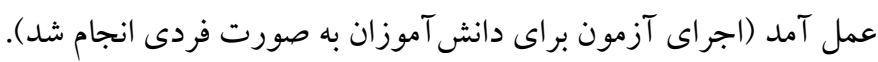

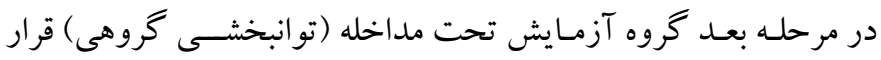

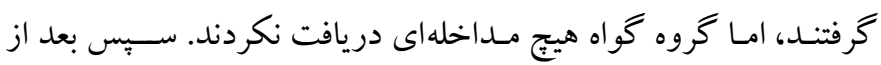

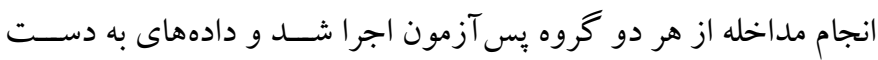

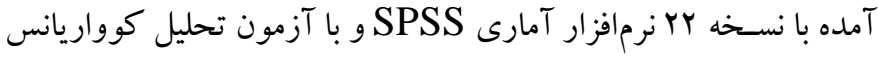
تككمتغيره مورد تجزيه و تحليل قرار كرفت.

جدول r: شاخصهاى توصيفى نمرات ييش آزمون- يس آزمون در دو كروه آزمايش و كنترل (تعداد: •r)

\begin{tabular}{|c|c|c|c|c|c|c|}
\hline $\mathbf{P}$ & شاييرو-ويلكز & انحراف استاندارد & ميانكين & كروه & وضعيت & متغير \\
\hline .109 &.$/ 99$ & $1 / F V$ & 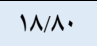 & آزمايش & \multirow{2}{*}{ بيش آزمون } & \multirow{4}{*}{ حل مسئله } \\
\hline$\cdot / F V$ &.$/ 9 F$ & $1 / \Gamma \wedge$ & $M / V r$ & كو اه & & \\
\hline$\cdot / \Delta F$ & $\cdot / 90$ & $1 / \mp \wedge$ & $r \cdot / N r$ & آزمايش & \multirow{2}{*}{ يֶ آزمون } & \\
\hline.$/ 11$ &.$/ 9$ & $1 / F \Delta$ & IN/AG & كواه & & \\
\hline
\end{tabular}

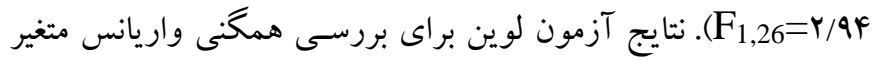

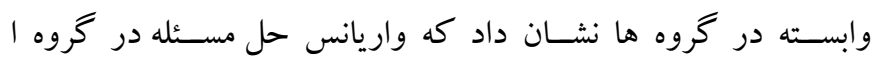

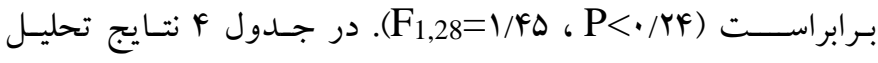

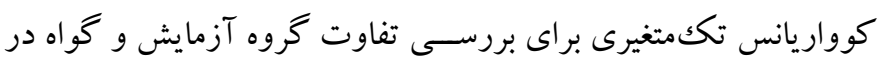

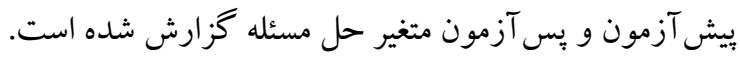

براى بررسى تأثير گروه درمانى تو انبخشى شناختى بر حل مسئله در

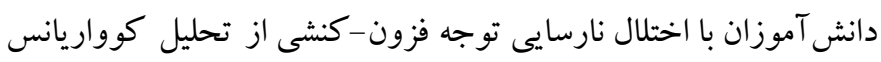

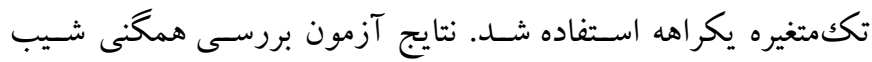

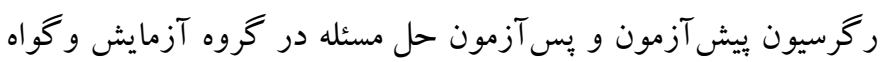

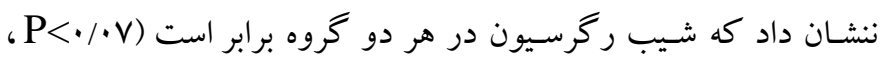

جدول با: نتايج تحليل كواريانس تك متغيره براى بررسى تفاوت كروه آزمايش و كواه در مهارت حل مسئله

\begin{tabular}{|c|c|c|c|c|c|c|}
\hline اندازه اثر & $\mathbf{P}$ & Tاره Fار & ميانكين مجذورات & درجه آزادى & مجموع مجذورات & منبع \\
\hline.$/ 99$ &.$/ \cdot 1$ & $\Delta \wedge V / V$ & $\Delta N / \cdot 1$ & 1 & $\Delta N \cdot 1$ & ي ييش آزمون \\
\hline \multirow[t]{2}{*}{.$/ 9$} & 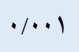 & YFA/V. & $Y F / T V$ & 1 & $Y F / Y V$ & عضويت گروهى \\
\hline & & &.$/ 1$. & rV & $r / 99$ & خطا \\
\hline
\end{tabular}


مـطلبوى بر ارتقـاى حـافظـه كـارى كودكـان مبتلـا بـه نـارســــي توجه/فزون كنشى دارد (TV-MY) (TV).

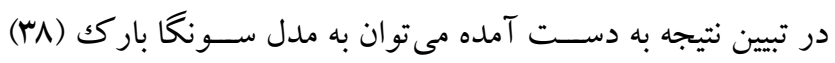

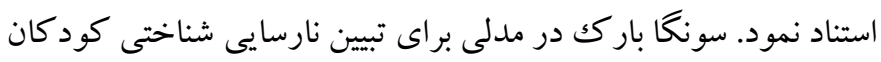

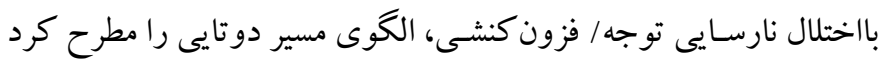

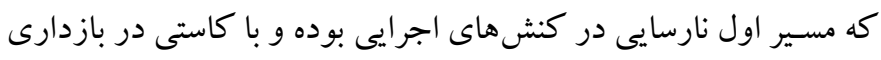

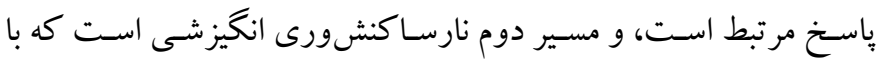

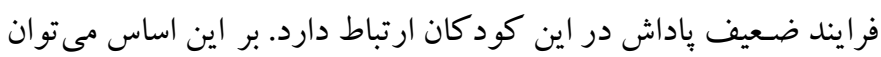
بر اسـاس فرضـيه شــكل يذيرى مغز اين گونه توضـيح داد كه تأثيرات احتمالى آموزش توانبخشى شـناختى در اثر تمرين هاى شناختى و تكرار

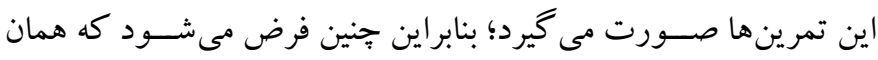

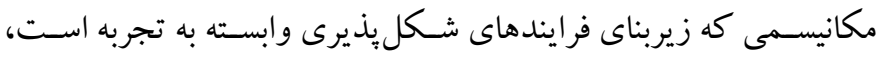

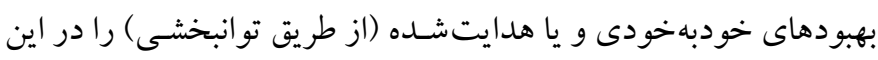

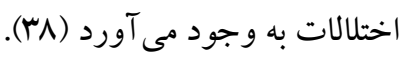

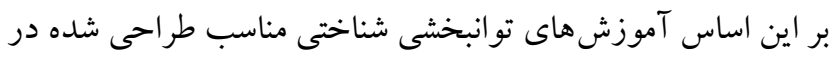
زمينه كنشهـاى اجر ايى مى تو انتـل بهبودهاى باثبات ترى رادي در اين زمينه

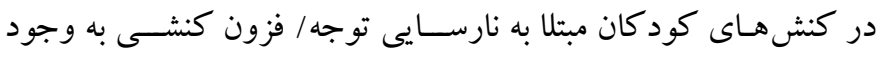

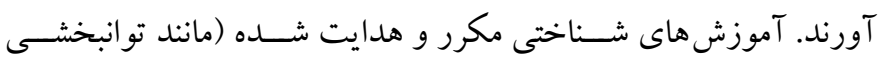
شناختى) باعث ييدايش تغييرات ساختارى و كنشى در نورونهاى مسئول اين كنشها، در مغز اين كود كان مىشوند؛ تغيير اتى كه با توجه به فرضيه

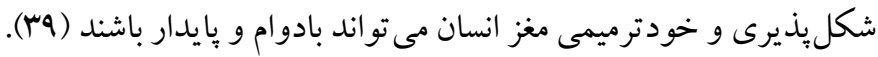

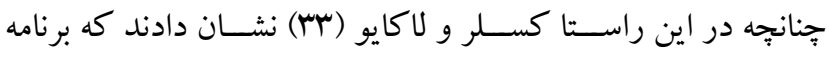
تو انبخشـى شــنـاختى رايـانهاى به طور قابل توجهى ســـرعت يردازش،

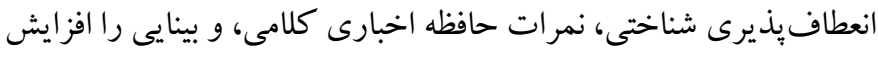

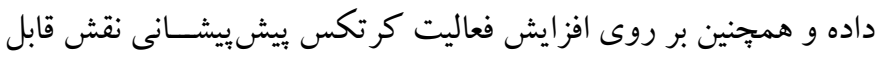
توجهى داشته است. مهمترين فرض روى آوردهاى شـناختى اين اسـت كه ياد گيرندههاى

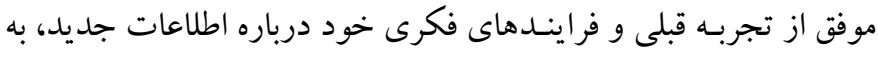

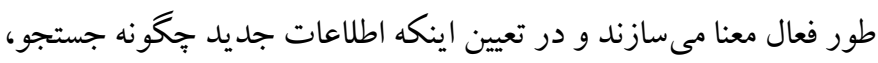
ادراكك، و طبقهبندى شــوند و با اطلاعات ذخيره شــــه قبلى ارتباط داده

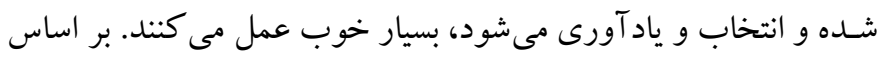

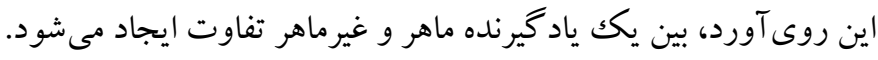

بـا توجـه بـه جدول ץ آماره F حل مســئله در پِس آزمون ( FFD/V)

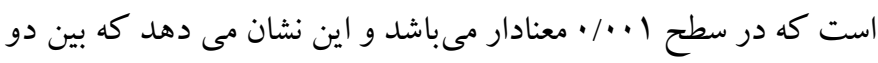

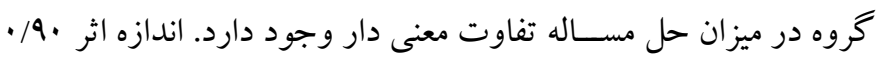

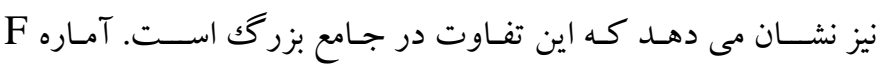

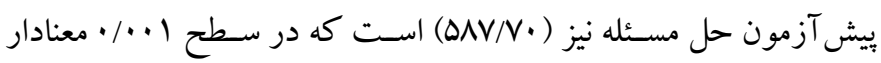
مىباشد. اين يافته نشان مى دهد كه ييش آزمون تأثير معنادارى بر نمرات بس آزمون دارد. نتايج تحليل كوواريانس نشـان داد كه ميانگين تصحيح

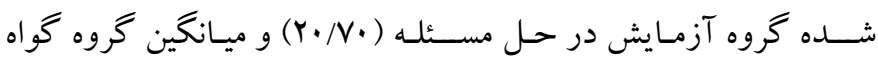

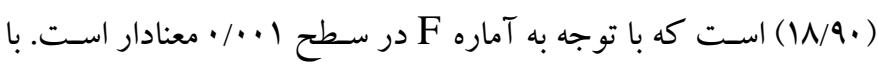

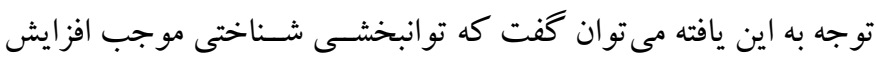
حل مسئله دانش آموزان با اختلال نارسايى توجه فزون-كنشى مى بـود.

\section{بحث و نتيجه كيرى}

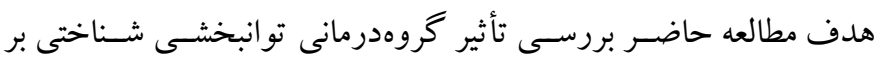

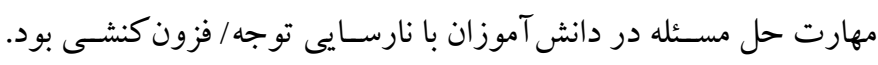

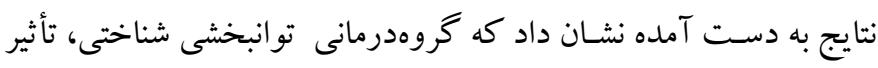

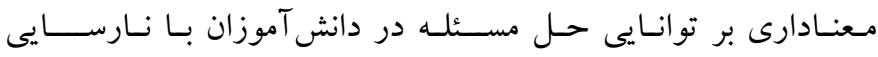

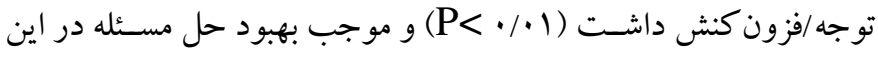

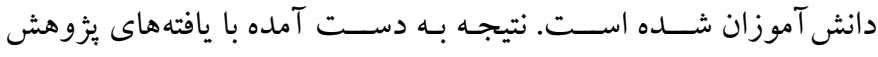

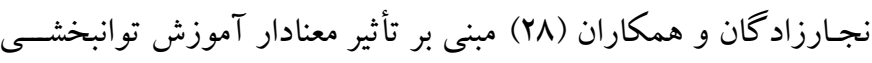
شـناختى بر كنشهاى اجرايى (حافظه كارى) در كود كان مبتلا به اختلال

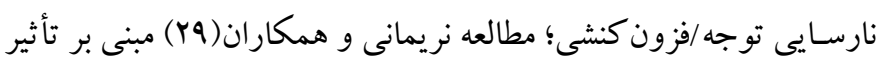

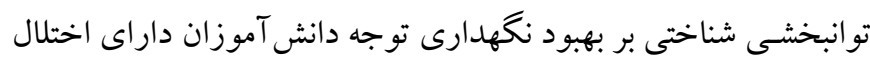
نارسـيايى توجه/فزون كنشى، همسو است. همجنين با نتايج مطالعه سازمان

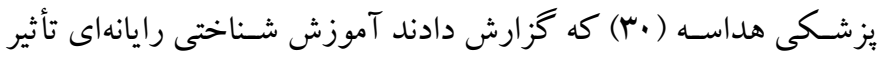

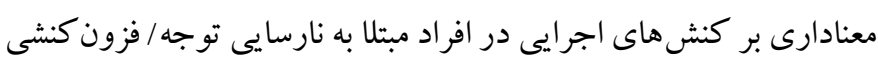

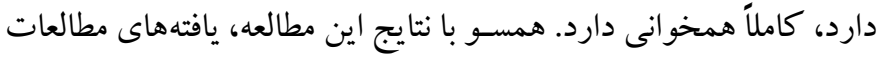

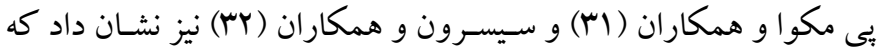
توانبخشى شـناختى بر بهبود كنش هاى اجرايى كود كان ، مؤثر است. از

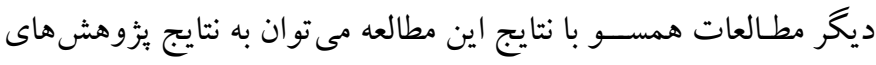
(TV - MY) 
مشـاوره دانش اموزان در مدرسـه و غربال كرى هاى للازم تا حدى كنترل

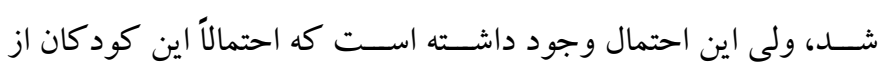

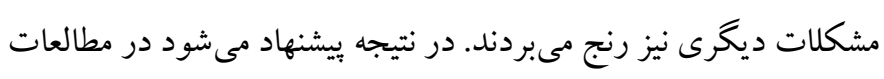

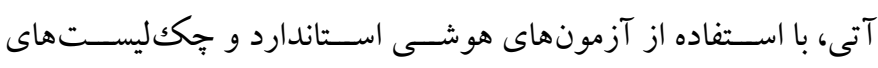

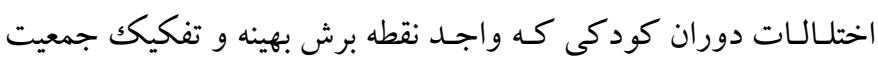
بهنجار از نابهنجار است، كنترل دقيقترى روى افراد نمونه انجام شود. در

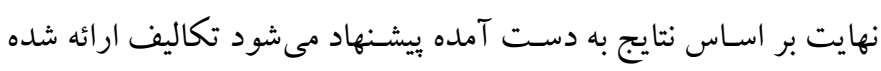

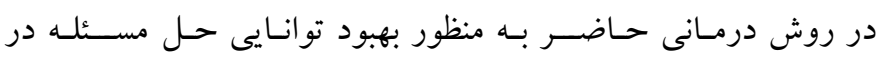

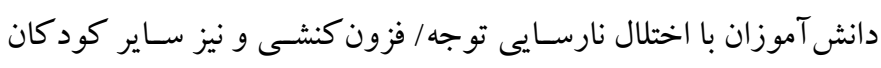
مبتلا به اختلالات مشابه، مورد استفاده قرار گيرد.

تشـكر و قدردانى: اين به صـورت مستقل اجرا شده است و مجوز اجراى آن

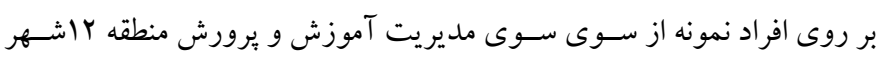

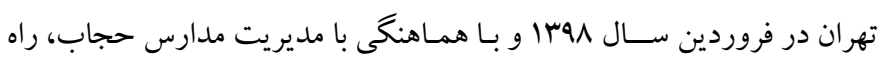

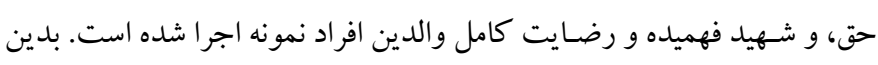

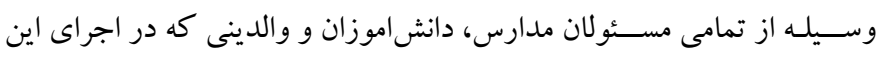
يزووهش مشار كت صادقانه داشتند، تشكر و قدردانى مى شود.

تضـاد منافع: اين مقاله حاصـل يكك بثروهش مسـتقل اسـت كه بدون حمايت

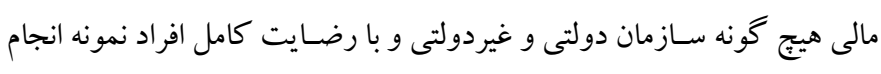

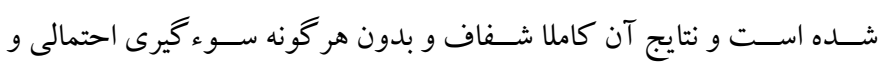

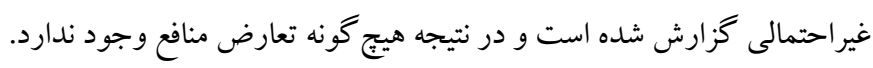

ناتوانى ياد گيرنده غيرماهر در استفاده مفيد و موثر از فراينـدهـاى اجر ايى

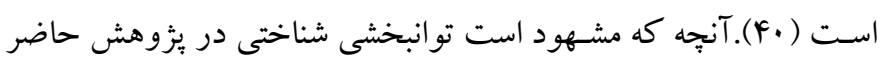

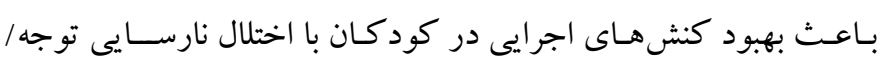

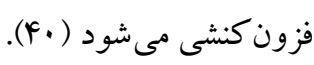

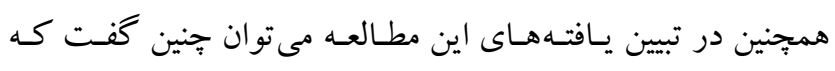

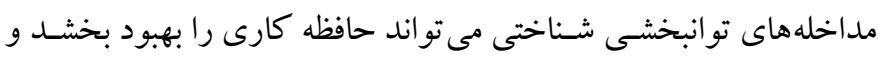

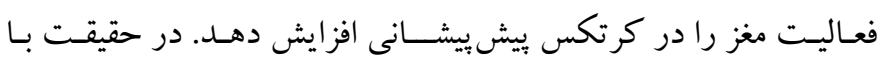

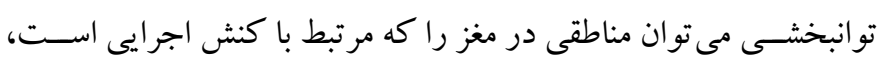

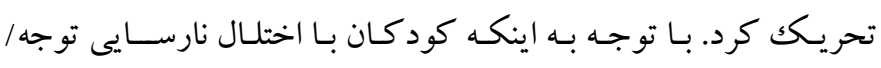

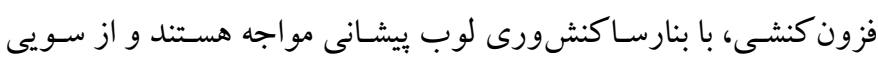

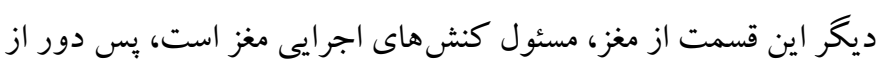

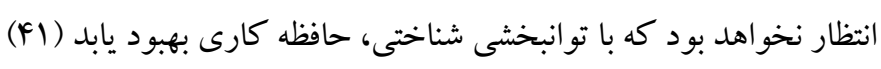
و توانايى حل مسئله افزايش يابد.

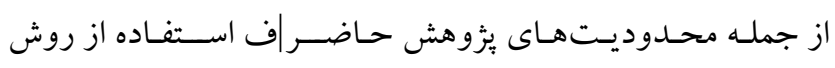
نمونه كيرى در دسترس و عدم كنترل وضعيت فرهنگك/ اجتماعى والدين

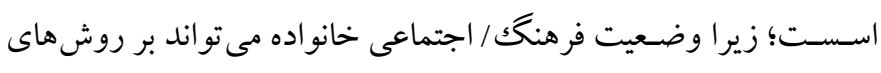

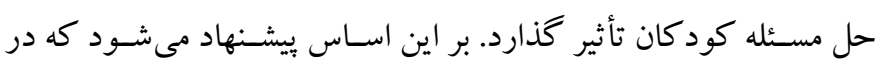

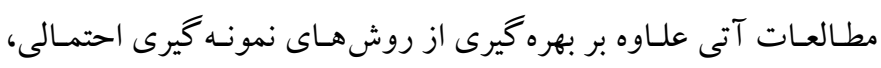

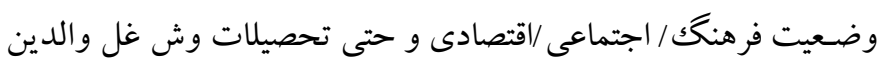

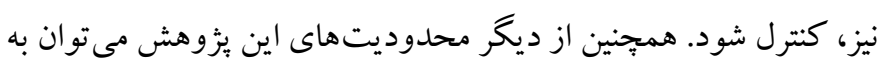

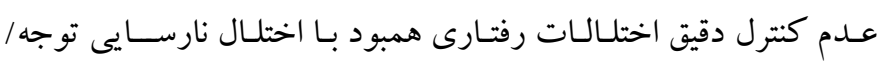
فزون كتنشسى اشـاره كرد؛ هرجند اين موضسوع تا حدى بـ با مطالعه برونده 


\section{References}

1. Kaneko F, Okamura H. Study on the social maturity, self-perception, and associated factors, including motor coordination, of children with attention deficit hyperactivity disorder. Phys Occup Ther Pediatr. 2006; 25(4):45-58. [Link]

2. Lufi D, Parish-Plass J. Sport-based group therapy program for boys with adhd or with other behavioral disorders. Child \& Family Behavior Therapy. 2013; 33(3): 217-230. [Link]

3. Masi G, Fantozzi P, Villafranca V, Tacchi T, Ricci F, Ruglioni L, et al. Effects of melatonin in children with attention deficit /hyperactivity disorder with sleep disorders after methylphenidate treatment. Neuropsychiatr Dis Treat. 2019; 15: 663-667. [Link]

4. American Psychological Association: APA. Diagnostic and Statistical Manual of Mental Disorders: Dsm-5. Washington DC: American Psychiatric Association Publishing; 2013, pp: 217317-326-343-487. [Link]

5. Kaplan HI, Sadock B. Comprehensive textbook of psychiatry. Philadelphia: William \& Wilkins; 2010, pp 189-202. [Link]

6. Zahiruddin A, Adineh M, Rajazi Isfahani S, Ahmadi A. The prevalence of attention deficit hyperactivity disorder among students of Shahid Beheshti University of Medical Sciences. Shahid Beheshti University of Medical Sciences. 2016; 6(4): 231-239. [Persian]. [Link]

7. Niusha B, Ganji K, Sotoudeh M. Outbreak of Attention Deficit / Hyperactivity Disorder Symptoms in Gifted Students in Kohgiluyeh and Boyer Ahmad Province. Journal of Psychology of Exceptional Persons. 2011; 2 (6): 93-61. [Persian]. [Link]

8. Kiyamasi A, Ilbeigi Ghale Nei R. Relationship of affinity and emotional insufficiency with life satisfaction in female students with ADHD symptoms. School Psychology. 2011; 1(1): 92-76. [Persian]. [Link]

9. Tehrani Doost M, Azadi B, Sedigh A, Ashrafi M. Impaired executive function in patients with phenylketonuria treated. 2005; 15: 25-35. [Persian]. [Link]

10. Elliot AJ, Gable SL, Mapes RR. Approach and avoidance motivation in the social domain. Pers Soc Psychol Bull. 2006; 32(2): 378-391. [Link]

11. Dreer L, Elliott T, Fletcher D, Swanson M. Social problem-solving abilities and psychological adjustment of persons in low vision rehabilitation. Rehabil Psychol. 2005; 50: 232-238.[Link]
12. Nicole M, Savannah L, King C, Hilton T, Rondon A. Social Functioning in Youth with AttentionDeficit/Hyperactivity Disorder and Sluggish Cognitive Tempo. Yale J Biol Med. 2019; 92(1): 2935. [Link]

13. Friend M. Special education contemporary perspectives for school professionals. Third edition. Upper Saddle River, NJ: Pearson Education; 2011, PP: 157-160. [Link]

14. Agran M, Wehmeyer M. Teaching problem solving to students with mental retardation. In: Wehmeyer ML, Agran M (Eds.), Mental retardation and intellectual disabilities teaching students using innovative and researchbased strategies, 2005; p: 255. [Link]

15. Ros R, Graziano PA. Social functioning in children with or at risk for attention deficit/hyperactivity disorder: a meta-analytic review. J Clin Child Adolesc Psychol. 2018; 47(2):213-35. [Link]

16. Friedman LM, Rapport MD, Orban SA, Eckrich SJ, Calub CA. Applied Problem Solving in Children with ADHD: The Mediating Roles of Working Memory and Mathematical Calculation. J Abnorm Child Psychol. 2018; 46(3):491-504. [Link]

17. Rinsky JR, Hinshaw SP. Linkages between childhood executive functioning and adolescent social functioning and psychopathology in girls with ADHD. Child Neuropsychol. 2011; 17(1): 368-390. [Link]

18. Dawson P, Guare R. The Guilford practical intervention in the schools series. Executive skills in children and adolescents: A practical guide to assessment and intervention (2nd Ed.). New York, NY, US: Guilford Press. 2010; PP: 57-60-63. [Link]

19. Schwitzer JB, Lee DO, Hanford RB, Zink CF, Ely TD, Tagamets MA, et al. Effect of methylphenidate on executive functioning in adults with attention deficit/hyperactivity disorder: normalization of behavior but not related brain activity. Biological Psychiatry. 2004; 56(8): 597-606.[Link]

20. Hechtman L, Abikoff H, Klein RG, Weiss G, Respitz $\mathrm{C}$, Kouri J, et al. Academic achievement and emotional status of children with ADHD treated with long-term methylphenidate and multimodal psychosocial treatment. American Academy of Child \& Adolescent Psychiatry. 2004; 43(7): 812-819. [Link]

21. Willis S, Tennstedt S, Marsiske M, Ball K, Elias J, Koepke K. Term effects of cognitive training on everyday functional outcomes in older adults. Journal American Medical Association. 2006; 196 (23): 28052814. [Link] 
22. Wolters G, Stapert S, Brands I, Van Heugten C. Coping styles in relation to cognitive rehabilitation and quality of life after brain an injure. Neuropsychol Rehabil. 2010; 20(4): 587-600. [Link]

23. Injoque-Ricle I, Burin D I. Working memory and planning in children: Validation of the Tower of London Task. Neuropsicología Latinoamericana. 2011; 3: 31-38. [Link]

24. Ten LF, Best JR, Chan JL, Ghag C, Erickson KI, Handy TC, et al. The Effects of Computerized Cognitive Training with and without Physical Exercise on Cognitive Function in Older Adults: An 8-week Randomized Controlled Trial. J Gerontol a Biol Sci Med Sci. 2019; 12(1): 31-38. [Link]

25. Veloso A, Vicente SG, Filipe MG. Effectiveness of Cognitive Training for School-Aged Children and Adolescents with Attention Deficit/Hyperactivity Disorder: A Systematic Review. Front Psychol. 2020; 10:1-17. [Link]

26. Simone M, Viterbo RG, Margari L, Iaffaldano P. Computer-assisted rehabilitation of attention in pediatric multiple sclerosis and ADHD patients: a pilot trial. BMC Neurol. 2018; 18(1):82. Published 2018 Jun 8. [Link]

27. Seyedmohammadi S, Ehteshamzade P, Hafezi F, Pasha R, Makvandy B. Effectiveness of cognitive rehabilitation after medication on brain function and behavioral symptoms of children with ADHD in Ahwaz. Shenakht Journal of Psychology and Psychiatry. 2019; 6 (3):102-117. [Link]

28. Najarzadegan M, NejatI V, Amiri N, Sharifian M. Investigating the effect of cognitive rehabilitation on executive functions (attention and work memory) in children with attention deficit hyperactivity disorder. Rehabilitation Medicine. 2014; 4 (2): 97-108. [Persian]. [Link]

29. Narimani M, Soleimani I, Tabrizchi N. The study of the effect of cognitive rehabilitation on improving the attention and academic achievement of students with ADHD disorder. School Psychology. 2014; 4(2): 118134. [Persian]. [Link]

30. Hadassah Medical Organization. The Efficacy of Computerized Cognitive Training in Adults with ADHD: Change in ADHD Symptoms, Executive Functions and Quality of Life Following Three Months of Training. History of Changes. 2011; 15(3):400- 430. [Link]

31. Pumaccahua TT, Wong EH, Eeist DJ. Effects of computerized cognitive training on working memory in a school setting. International Journal of Learning. 2017; 16(3): 88-104. [Link]
32. Cicerone KD, Langenbahn DM, Braden C, Malec JF, Kalmar K, Fraas M, \& et al. Evidence-based cognitive rehabilitation: up dated review of the literature from 2003 through 2008. Archives Physical Medicine and Rehabilitation. 2011; 92(4):519-530. [Link]

33. Kesler SR, Lacayo NJ, Jo B. A pilot study of an online cognitive rehabilitation program for executive function skills in children with cancer-related brain injury. Department of Psychiatry and Behavioral Sciences, Stanford University. 2011; 25(1):101-12. [Link]

34. Jalili F, Nejati V, Ahadi H, Katanforosh S A. Effectiveness of computerized motion-based cognitive rehabilitation on improvement of working memory of children with ADHD . Medical Sciences. 2019; 29 (2):171-180. [Persian]. [Link]

35. Robatmili S. The Effect of Computer-Assisted Cognitive Rehabilitation on Working Memory in Children with ADHD. International Journal of Psychology. 2019; 13(1): 183-205. [Link]

36. Alidadi Taeme F, Sotodeh Asl N, Karami A. The Effect of Cognitive Rehabilitation and Neurofeedback on improving Working Memory in children with Attention Deficit Hyperactivity Disorder. Iranian Journal of Rehabilitation Research in Nursing (IJRN). 2019; 6(1): 27-33. [Persian]. [Link]

37. Tajik-Parvinchi D, Wright L, Schachar R. Cognitive Rehabilitation for Attention Deficit/Hyperactivity Disorder (ADHD): Promises and Problems. J Can Acad Child Adolesc Psychiatry. 2014; 23(3):207217.[Link]

38. Sonuga Bark EJ. The dual pathway model of ADHD. Neurosci Biobehav Rev. 2003; 27: 593-604. [Link]

39. Bayrami M, Movahedi Y. The effect of softwarebased neuroscience rehabilitation on improving problem-solving performance in people with reading disability. Society Health Journal. 2018; 12 (36): 3037. [Persian]. [Link]

40. Yavari Barhaghtalab E, Asgary P, Naderi F, Heidarie AR. Effect of Cognitive Rehabilitation Therapy on Performance (Memory and Problem Solving) of Children with Attention Deficit Hyperactivity Disorder. J Rehab Med. 2020; 8(4): 165-176. [Link]

41. Aivazy S, Yazdanbakhsh K, Moradi A. The Effectiveness of cognitive rehabilitation on improvement of working memory in children with attention deficit/ hyperactivity disorder. Neuropsychology. 2019; 5(1): 121-134. [Link]

42. Sprafkin J, Gadow KD, Salisbury H, Schneider J, Long J. Further evidence of reliability and validity of the child symptom Inventory-4: parent checklist in 
clinically referred boys. Department of psychiatry. J Clin Child Adolesc Psychol. 2002; 31(4):513-24. [Link]

43. Mohammad Esmaeil E, Alipour A. Preliminary evaluation of validity and reliability and determining the cut-off points of the disordered children's questionnaire (CSI-4). Quarterly Journal of Exceptional Children. 2001; 2(3): 239-254. [Persian]. [Link]

44. Lezak MD, Howieson DB, Loring DW. Neuropsychological Assessment, 4th edition. New York: Oxford University Press; 2004, P: 116. [Link]

45. Shallice T. Specific impairments of planning. Philosophical Transactions of the Royal Society B: Biological Sciences. 1982; 298(1089): 199-209. [Link]
46. Taqavi Jelodar M, Hami M. The Effectiveness of Computer Games on the Problem Solving of Children. Journal of Evaluation and Measurement. 2018; 11(42):55-70. [Persian]. [Link]

47. Nazari M, Mohammad Jananya S, Karimi Dawrabi E. Cognitive and motor empowerment package for the prevention of various disorders. Creation Education Department; 2014. [Persian]. [Link]

48. Yazdanbakhsh K, Eyvazi S, Moradi A. The Effectiveness of Cognitive Rehabilitation on Working Memory on Improving Sleep Problems and Behavioral Syndrome in Children with Attention Deficit / Hyperactivity Disorder. Quarterly of Psychology of Exceptional Individuals. 2018; 8 (29):213-234. [Persian]. [Link] 